\title{
A Slow Outward Current Activated by FMRFamide in Heart Interneurons of the Medicinal Leech
}

\author{
Farzan Nadim and Ronald L. Calabrese \\ Department of Biology, Emory University, Atlanta, Georgia 30322
}

The endogenous neuropeptide FMRFamide (Phe-Met-ArgPhe- $\mathrm{NH}_{2}$ ) can accelerate the oscillation of reciprocally inhibitory pairs of interneurons that pace heartbeat in the medicinal leech. A model based on all available biophysical data of a two-cell heart interneuron oscillator provides a theoretical basis for understanding this modulation. Previously observed modulation of $\mathrm{K}^{+}$currents by FMRFamide cannot account for this acceleratory effect in the model. This observation prompted the present reexamination of $\mathrm{K}^{+}$currents in heart interneurons. We devised better methods for separation of the various compo- nents of $\mathrm{K}^{+}$current and more accurately measured their activation and deactivation kinetics. Moreover, we demonstrated that FMRFamide activates a previously undetected $\mathrm{K}^{+}$current $\left(I_{\mathrm{KF}}\right)$, which has very slow activation and deactivation kinetics. Addition of physiologically measured amounts of $I_{\mathrm{KF}}$ to the model two-cell oscillator can account for the acceleratory effect of FMRFamide.

Key words: FMRFamide; slow outward currents; neural oscillator; conductance-based model; leech; $\mathrm{K}^{+}$
Rhythmic motor patterns, such as feeding and chewing, locomotion, breathing, and heartbeat (in certain invertebrates), are programmed in part by rhythmically active neural networks called pattern generators (Delcomyn, 1980). Oscillation in these networks derives from the interplay of the inherent membrane properties of the component neurons and their synaptic interactions (Getting, 1989; Jacklet, 1989; Arshavsky et al., 1993; HarrisWarrick, 1993; Rossignol and Dubuc, 1994; Dean and Cruse, 1995; Marder and Calabrese, 1996). To produce adaptive behavior, these pattern generators must respond to the changing internal and external needs of the animal by producing motor outflow that is gated on or off or is altered in its frequency, strength, and activity phases. Numerous studies have indicated that both synaptic interactions and membrane properties can be modulated to effect these changes (for reviews, see Harris-Warrick and Marder, 1991; Dickinson, 1995; Katz, 1996). Often more than one neuron, synapse, or membrane property is altered by a modulatory substance that produces an adaptive change in motor output (e.g., Johnson et al., 1995), so that it can be difficult to determine which modulated parameters(s) is critical for producing a given motor outflow (Harris-Warrick et al., 1995). The use of computer modeling studies and hybrid simulation tools such as the dynamic clamp (Sharp et al., 1993) have been fruitful in identifying such critical parameters (Golowasch et al., 1992; Sharp et al., 1993; Harris-Warrick et al., 1995).

We have been studying the pattern generator for heartbeat in the medicinal leech and its modulation by the endogenous (Evans et al., 1991) neuropeptide FMRFamide (Phe-Met-Arg-Phe- $\mathrm{NH}_{2}$ ) (for a recent review, see Calabrese et al., 1995). Activity in the FMRFamide immunoreactive cell 204 or bath application of the

Received Nov. 27, 1996; revised March 17, 1997; accepted March 21, 1997.

This work was supported by National Institutes of Health Grants NS24072 and NS34975.

Correspondence should be addressed to Ronald L. Calabrese, Department of Biology, Emory University, 1510 Clifton Road, Atlanta, GA 30322.

Dr. Nadim's present address: Volen Center, Brandeis University, Waltham, MA 02254.

Copyright (C) 1997 Society for Neuroscience $0270-6474 / 97 / 174461-12 \$ 05.00 / 0$ peptide $\left(\leq 5 \times 10^{-8} \mathrm{M}\right)$ increases the cycle rate of this pattern generator (Simon et al., 1992). Bath application of higher concentrations of FMRFamide leads to a disruption of rhythmic activity (Simon et al., 1992). The "beat timing oscillator" that paces this pattern generator consists of two bilateral pairs of reciprocally inhibitory segmental interneurons that are linked together by two pairs of segmental coordinating interneurons (Calabrese et al., 1995). Each of these reciprocally inhibitory pairs can act as an independent elemental oscillator, when the segmental ganglion in which they reside is isolated from the rest of the ventral nerve cord. In such reduced preparations, bath-applied FMRFamide exerts both its acceleratory and disruptive effects on the elemental oscillators (Simon et al., 1992).

Here we report experimental studies that identify a new voltage-gated outward current that is modulated by FMRFamide and can account for the acceleratory effect of FMRFamide when incorporated into our conductance-based model of a heart interneuron elemental oscillator.

\section{MATERIALS AND METHODS}

Leeches (Hirudo medicinalis) were obtained from Leeches USA and Biopharm and maintained in artificial pond water at $15^{\circ} \mathrm{C}$. After the animals were anesthetized in ice-cold saline, individual ganglia were dissected and pinned in small petri dishes. Ganglia were superfused continuously with normal leech saline containing (in $\mathrm{mM}$ ): $115 \mathrm{NaCl}, 4$ $\mathrm{KCl}, 1.8 \mathrm{CaCl}_{2}, 10$ glucose, 10 HEPES buffer; adjusted to $\mathrm{pH} 7.4$. Equimolar amounts of $N$-methyl-D-glucamine and $\mathrm{Co}^{++}$replaced $\mathrm{Na}^{+}$ and $\mathrm{Ca}^{2+}$, respectively, in $0 \mathrm{Na}^{+}, 0 \mathrm{Ca}^{2+}$ solutions. FMRFamide (Bachem, Torrance, CA) was dissolved in HPLC-grade water at a concentration of $10^{-3} \mathrm{M}$, stored frozen, and diluted to $10^{-6} \mathrm{M}$ in physiological saline immediately before use; it was applied at this concentration in all experiments described herein.

Cells were penetrated with borosilicate microelectrodes $(1 \mathrm{~mm}$ outer diameter, $0.75 \mathrm{~mm}$ inner diameter) filled with $4 \mathrm{M}$ potassium acetate with $20 \mathrm{~mm} \mathrm{KCl}(20-35 \mathrm{M} \Omega$ ). Electrodes were coated with Sylgard 182 (Dow Corning) up to $\sim 50 \mu \mathrm{m}$ from the tip to reduce capacitance. Currents were measured using switching single-electrode voltage clamp (Axoclamp 2A, Axon Instruments, Foster City, CA). Sample rates were between 2.9 and $3.5 \mathrm{kHz}$, and clamp gain was from 8 to $50 \mathrm{nA} / \mathrm{mV}$. The output bandwidth was set at $0.3 \mathrm{kHz}$. At the end of the experiment, microelectrodes were withdrawn from the cell and only those preparations in which 
the electrode was within $\pm 5 \mathrm{mV}$ of the bath potential were accepted. Voltage steps were generated by a computer (PC with 486 processor), and data were digitized and stored using pCLAMP software (Axon Instruments). The measurement of time constants was performed with CLAMPFIT 6.0, and leak subtractions were performed on a Sun SPARCstation LX. Deactivation-the opposite process from activation, i.e., closing of the "activation gate"-was measured after an activating voltage step, after returning to a more hyperpolarized potential. Because currents measured in FMRFamide deactivated slowly, the automatic leaksubtraction protocol of pCLAMP (using one or several hyperpolarizing voltage steps before each depolarizing step and adding the resulting currents) was not used. Instead, we applied 4-10 hyperpolarizing steps, of magnitude $10 \mathrm{mV}$ and duration $4 \mathrm{sec}$, both before and after each experimental protocol. We used the average leak current from all these steps to leak-subtract the currents measured with depolarizing steps.

The simulations were performed with Neurolab (Olsen, 1994) on a Sun SPARCstation LX and on a PC with Pentium processor under Linux. The simulations were performed using a variable time-step method (LSODES). The ionic currents in the model are given by HodgkinHuxley type equations (Hodgkin and Huxley, 1952) and are described in detail in Nadim et al. (1995) and Olsen et al. (1995).

\section{RESULTS}

\section{Rationale for the reexamination of outward currents in heart interneurons}

Several ionic currents have been identified in single-electrode voltage-clamp studies that contribute to the activity of oscillator heart interneurons. These include, in addition to the fast $\mathrm{Na}^{+}$ current that mediates spikes and the leak current $\left(I_{1}, E_{\mathrm{rev}}=-52.5\right.$ $\mathrm{mV}$ ), two low-threshold $\mathrm{Ca}^{2+}$ currents (Angstadt and Calabrese, 1991) [one rapidly inactivating $\left(I_{\mathrm{CaF}}\right)$ and one slowly inactivating $\left(I_{\mathrm{CaS}}\right)$ ]; three outward currents (Simon et al., 1992) [a fast transient $\mathrm{K}^{+}$current $\left(I_{\mathrm{A}}\right)$ and a delayed rectifier-like $\mathrm{K}^{+}$current $\left(I_{\mathrm{K}}\right)$, consisting of an inactivating $\left(I_{\mathrm{K} 1}\right)$, component and a persistent $\left(I_{\mathrm{K} 2}\right)$ component]; a hyperpolarization-activated inward current (DiFrancesco and Noble, 1989) $\left(I_{\mathrm{h}}\right)\left[\right.$ mixed $\mathrm{Na}^{+} / \mathrm{K}^{+}, E_{\mathrm{rev}}=-20$ $\mathrm{mV}$ ] (Angstadt and Calabrese,, 1989); and a low-threshold persistent $\mathrm{Na}^{+}$current $\left(I_{\mathrm{P}}\right)$ (Opdyke and Calabrese, 1994). The inhibition between oscillator interneurons consists of a graded component that is associated with the low-threshold $\mathrm{Ca}^{2+}$ currents (Angstadt and Calabrese, 1991) and a spike-mediated component that seems to be mediated by high-threshold $\mathrm{Ca}^{2+}$ current (Simon et al., 1994; Lu et al., 1997). Blockade of synaptic transmission with bicuculline leads to tonic activity in oscillator heart interneurons (Schmidt and Calabrese, 1992).

Much of this biophysical data was incorporated into a conductance-based model of an elemental (two-cell) oscillator (Nadim et al., 1995; Olsen et al., 1995), using standard HodgkinHuxley (Hodgkin and Huxley, 1952) representations of each voltage-gated current. The model also contains explicit independent formulations for both spike-mediated and graded synaptic transmission (Calabrese and De Schutter, 1992; De Schutter et al., 1993; Nadim et al., 1995). The model generates activity that closely approximates that observed for an elemental oscillator under control and various experimental conditions. This model has recently been tested experimentally by voltage clamping oscillator interneurons with realistic waveforms and has proved to be reliable (Olsen and Calabrese, 1996).

Voltage-clamp and current studies of oscillator interneurons have revealed several modulatory effects of FMRFamide (bath applied), including (1) negative shifts in the steady-state activation and inactivation of $I_{\mathrm{K}}$ (Simon et al., 1992), (2) activation of an $I_{\mathrm{P}}$-like current (Schmidt et al., 1995), and (3) an apparent reduction in spike-mediated synaptic transmission (Simon et al., 1994). In preliminary studies using our model, we have found that none

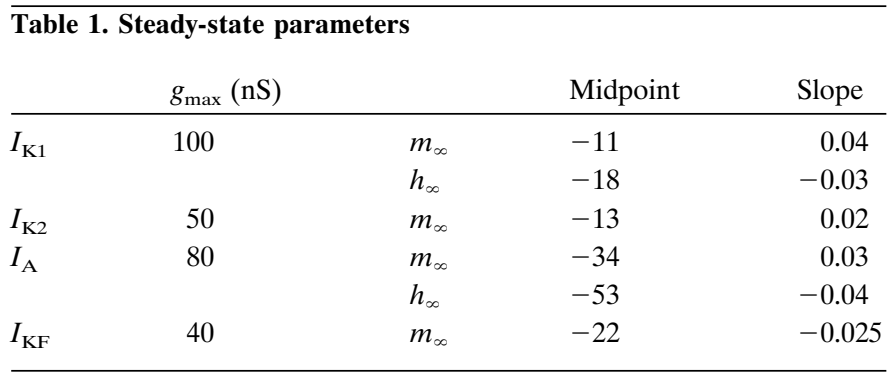

of these effects satisfactorily account for the acceleratory effect of FMRFamide on the oscillator interneurons, although they can account for the disruptions observed at higher concentrations. These observations have led us to reexamine outward currents in oscillator heart interneurons and their modulation by FMRFamide.

\section{The outward current in heart interneurons comprises three components}

We measured leak-subtracted outward currents in heart interneurons in $0 \mathrm{Na}^{+}, 0 \mathrm{Ca}^{2+}, 1.8 \mathrm{mM} \mathrm{Co}^{++}$saline. Our measurements confirmed those of Simon et al. (1992). When the cells were held at $-70 \mathrm{mV}$ and activated by depolarizing pulses, two outward currents were present: a fast, transient current $I_{\mathrm{A}}$ and a slower current $I_{\mathrm{K}}$, which only partially inactivated. When the cells were voltage-clamped at $-35 \mathrm{mV}$, depolarizing pulses produced only $I_{\mathrm{K}}$, indicating that the transient current $I_{\mathrm{A}}$ was completely inactivated at $-35 \mathrm{mV}$. Use of $1.5 \mathrm{sec}$ or longer depolarizing pulses revealed that $I_{\mathrm{K}}$ itself comprised two components: a component $\left(I_{\mathrm{K} 1}\right)$ that inactivated with a time constant of 400-800 msec, and a component $\left(I_{\mathrm{K} 2}\right)$ that was either noninactivating or inactivated with a time constant $>3$ sec. Figure 1 shows the outward current elicited using a $4 \mathrm{sec}$ pulse to $0 \mathrm{mV}$, from the holding potential of $-70 \mathrm{mV}$, together with fits to $I_{\mathrm{A}}, I_{\mathrm{K} 1}$, and $I_{\mathrm{K} 2}$. We used data described in this manuscript together with data from Simon et al. (1992) to obtain mathematical fits. The fits were made using Hodgkin-Huxley kinetic models (Hodgkin and Huxley, 1952) and were calculated using voltage-dependent time constants and steady states. The ionic currents were represented as:

$$
I=g_{\max } m^{2} h^{\mathrm{q}}\left(V-E_{\mathrm{K}}\right),
$$

where $q=1$ for $I_{\mathrm{A}}$ and $I_{\mathrm{K} 1}$, and $q=0$ for $I_{\mathrm{K} 2}$. The activation variable $m$ (similarly for the inactivation variable $h$ ) was governed by the differential equation:

$$
\tau(V) d m / d t=m_{\infty}(V)-m
$$

The steady-state activation curve $m_{\infty}$ (similarly for $h_{\infty}$ ) is given by the sigmoid:

$$
m_{\infty}(V)=1 /(1+\exp (-4 \operatorname{slope}(V-\text { midpoint }))) .
$$

The parameters are given in Tables 1 and 2 .

\section{Oscillation in model heart interneurons is sensitive to the activation kinetics of $I_{K 1}$ and $I_{K 2}$}

Using our model of oscillator heart interneurons (Nadim et al., 1995), we have looked at the possible extent and range of activation of the outward currents during oscillations. A sensitivity analysis of the oscillations in the model cells had revealed that the period is particularly sensitive to variations in the maximal conductance of $I_{\mathrm{K} 1}$ and $I_{\mathrm{K} 2}$ (Olsen et al., 1995). In our model we used equations derived by Simon et al. (1992), in which $I_{\mathrm{K} 1}$ activated 

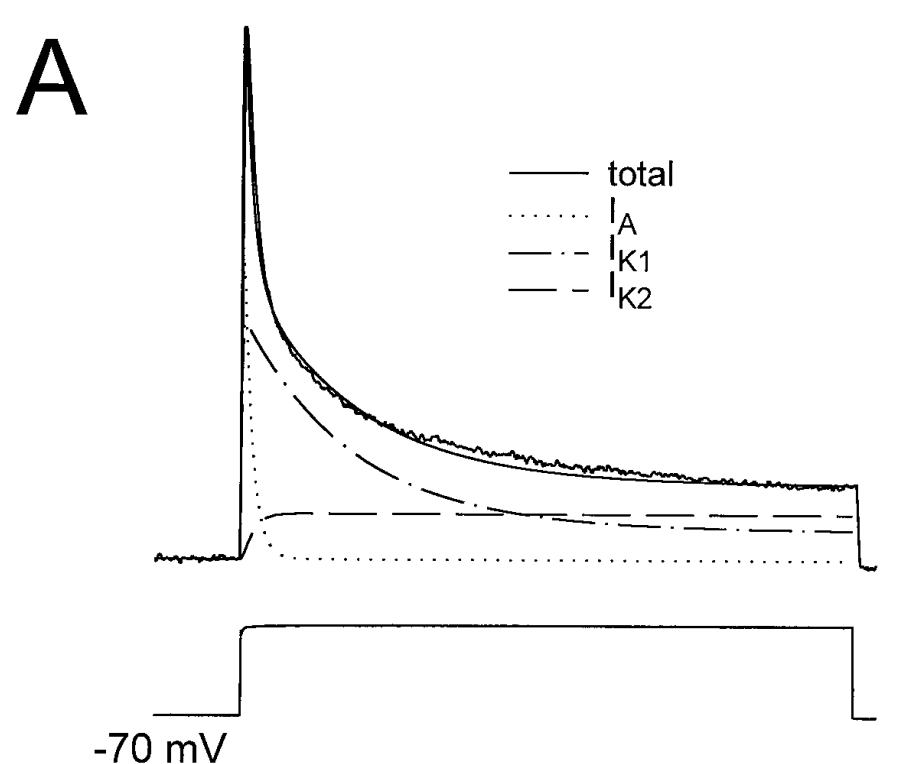

$-70 \mathrm{mV}$

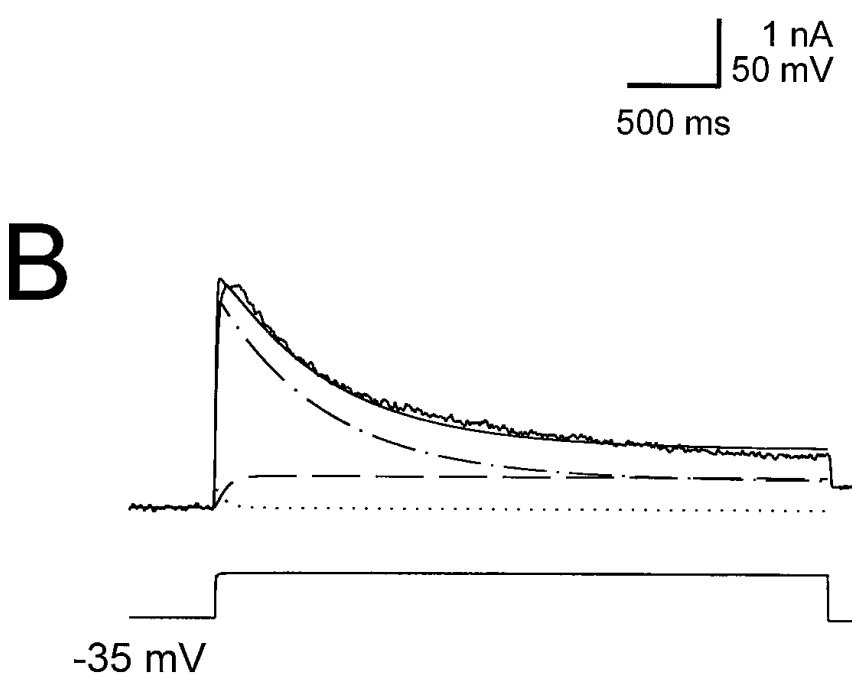

Figure 1. The outward currents measured in the heart interneurons. The outward currents comprise a rapidly inactivating $I_{\mathrm{A}}$, and a delayed rectifier consisting of a slowly inactivating component $I_{\mathrm{K} 1}$ and a persistent component $I_{\mathrm{K} 2}$. A, Outward currents measured in heart interneurons (ganglion 4), in response to a $4 \mathrm{sec}$ voltage step from $-70 \mathrm{mV}$ to $0 \mathrm{mV}$. Also shown are the fit to the current using parameters given in Tables 1 and 2, and the three components of the fit: $I_{\mathrm{A}}, I_{\mathrm{K} 1}$, and $I_{\mathrm{K} 2}$. $B$, Outward currents measured in the same cell, in response to a $4 \mathrm{sec}$ voltage step from $-35 \mathrm{mV}$ to $0 \mathrm{mV}$. Also shown are the trace fit to the current using parameters given in Tables 1 and 2. The holding potential of $-35 \mathrm{mV}$ almost completely inactivates $I_{\mathrm{A}}$, the component of the current that gives the fast transient peak.

and deactivated rapidly ( $\tau=1-12 \mathrm{msec}$ ), and $I_{\mathrm{K} 2}$ activated and deactivated slowly ( $\tau=60-100 \mathrm{msec}$ ). With these equations, our canonical model produced oscillations with a period of $7.5 \mathrm{sec}$ (Fig. $2 A$ ). Varying time constants of activation and deactivation of $I_{\mathrm{K} 1}$ and $I_{\mathrm{K} 2}$ affected the period and amplitude of the model oscillation. By making the activation rate of $I_{\mathrm{K} 2}$ as fast as that of $I_{\mathrm{K} 1}$ (but keeping the deactivation slow), the period of oscillations was reduced to $3.6 \mathrm{sec}$ (Fig. $2 \mathrm{~B}$ ). Measurements of $I_{\mathrm{K} 2}$ during these model oscillations showed that the activation variable $(m)$ of

\begin{tabular}{l} 
Table 2. Time constants of activation and inactivation \\
$\qquad$\begin{tabular}{l}
$\tau_{\mathrm{m} 1}(V)=1+11 /(1+\exp (0.15(V+6)))$ \\
$\tau_{\mathrm{h}}(V)=500+200 /(1+\exp (-0.143(V+3)))$ \\
$\tau_{\mathrm{m}}(V)=50+45 /(1+\exp (0.1(V+50)))$ \\
$I_{\mathrm{K} 2}(V)=5+11 /(1+\exp (0.2(V+20)))$ \\
$I_{\mathrm{A}}$ \\
$\tau_{\mathrm{m}}(V)=14+15 /(1+\exp (-0.22(V+21)))$ \\
$I_{\mathrm{KF}}$ \\
$\tau_{\mathrm{m}}(V)=1500+8000 /(1+\exp (-0.1(V+22)))$ \\
\\
\hline
\end{tabular} \\
\hline
\end{tabular}

$I_{\mathrm{K} 2}$ integrated rapidly with action potentials, without deactivating fast. Therefore, there was more $I_{\mathrm{K} 2}$ available during the burst phase of the oscillations compared with the canonical case. The increase in $I_{\mathrm{K} 2}$ reduced the spike frequency and caused the speed-up of the oscillation. [See Olsen et al. (1995) for a discussion of the effect of spike frequency on the period of oscillations.]

By making the deactivation rate of $I_{\mathrm{K} 2}$ as fast as that of $I_{\mathrm{K} 1}$ (but keeping the activation slow), the period of oscillations was increased to $10.6 \mathrm{sec}$ (Fig. $2 C$ ). The activation variable $(m)$ of $I_{\mathrm{K} 2}$ was set back to almost zero with the repolarization after each action potential. There was little accumulation of $I_{\mathrm{K} 2}$ during the burst, and the current became small compared with the canonical case. If both activation and deactivation of $I_{\mathrm{K} 2}$ were fast, then the model cells could not support action potentials on the bursting plateau (Fig. 2D). The failure to support action potentials was caused by inactivation of the fast $\mathrm{Na}^{+}$current $I_{\mathrm{Na}}$, which is responsible for spiking. When deactivation of $I_{\mathrm{K} 2}$ is slow, there is sufficient removal of inactivation from $I_{\mathrm{Na}}$ during the intervals between action potentials. Therefore, action potentials do not fail merely by making the activation of $I_{\mathrm{K} 2}$ fast. If the activation time constant of $I_{\mathrm{K} 2}$ was decreased gradually (both in the activation and in the deactivation range), then initially the effect of fast deactivation was dominant and the period of oscillation increased; subsequently, as time constants were made faster, spiking ceased and model cells produced oscillations as shown in Figure 2D. These theoretical studies pointed out the importance of the kinetics of outward currents in determining the period of oscillation, and thus motivated a careful experimental reevaluation of the activation and deactivation kinetics of $I_{\mathrm{K} 2}$ and the effects of FMRFamide on these parameters.

\section{Activation and deactivation kinetics of $\boldsymbol{I}_{\boldsymbol{K} 2}$}

Simon et al. (1992) measured activation and deactivation kinetics of $I_{\mathrm{K}}$. They voltage-clamped cells at $-35 \mathrm{mV}$ to inactivate $I_{\mathrm{A}}$, used $150 \mathrm{msec}$ depolarizing pulses to measure activation time constants, and used a $75 \mathrm{msec}$ prepulse to $20 \mathrm{mV}$, followed by postpulses to a range of potentials, to measure deactivation time constants. The protocol they used, therefore, measured activation and deactivation time constants for the sum of both $I_{\mathrm{K} 1}$ and $I_{\mathrm{K} 2}$. We were interested in obtaining activation and deactivation time constants for $I_{\mathrm{K} 2}$ separately, to see any difference in the activation kinetics of $I_{\mathrm{K} 1}$ and $I_{\mathrm{K} 2}$. We could not separate the currents pharmacologically; thus it was not possible to measure the activation kinetics of $I_{\mathrm{K} 1}$ and $I_{\mathrm{K} 2}$ separately. We made use of the inactivation of $I_{\mathrm{K} 1}$ to isolate $I_{\mathrm{K} 2}$ and measure its deactivation kinetics in a range of membrane potentials that was as wide as possible. Because deactivation is generally believed to be the opposite process to activation, the kinetics measured would provide information about the activation kinetics of $I_{\mathrm{K} 2}$ as well. Deactivation time constants of $I_{\mathrm{K}}$ were measured by holding the cell at $-35 \mathrm{mV}$ and applying a prepulse to $0 \mathrm{mV}$ to activate the 
A canonical

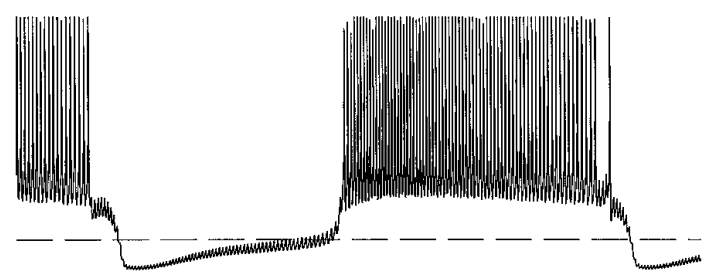

B

$\mathrm{I}_{\mathrm{K} 2}$ fast activation

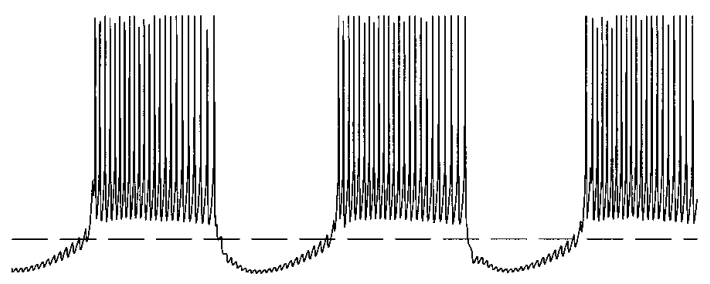

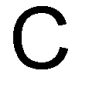

$\mathrm{I}_{\mathrm{K} 2}$ fast deactivation

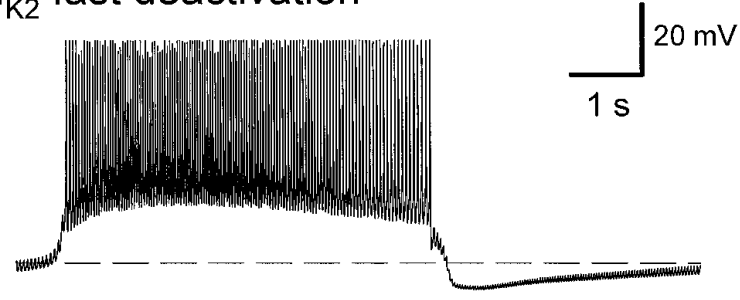

$\mathrm{I}_{\mathrm{K} 2}$ fast activation
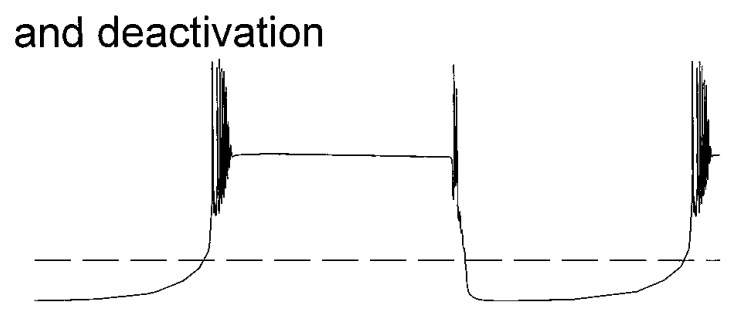

Figure 2. A $10 \mathrm{sec}$ window of the oscillation in one heart interneuron of a model elemental oscillator (two reciprocally inhibitory cells). Dashed line denotes membrane potential of $-50 \mathrm{mV}$. The values of time constants are given in Table 2. A, Bursting oscillation of a model cell using canonical parameters of the ionic and synaptic currents, as described in Nadim et al. (1995). The period of the canonical oscillation is $7.5 \mathrm{sec} . B$, Model cell oscillation where the activation time constant of $I_{\mathrm{K} 2}$ is changed from its canonical value to be as fast as the activation time constant of $I_{\mathrm{K} 1}$. The period has decreased to $3.6 \mathrm{sec}$. $C$, Model cell oscillation where the deactivation time constant of $I_{\mathrm{K} 2}$ is changed from the canonical value to be as fast as the deactivation time constant of $I_{\mathrm{K} 1}$. The period has increased to 10.6 sec. $D$, Model cell oscillation where time constants of both activation and deactivation of $I_{\mathrm{K} 2}$ are fast. In this case, the model cells cannot support action potentials on the plateau.

current, followed by a postpulse at various membrane potentials. Two sets of experiments were performed: one used a $100 \mathrm{msec}$ prepulse (Fig. $3 A$ ) and the other used a $4 \mathrm{sec}$ prepulse (Fig. $3 B$ ). Time constants of deactivation were obtained from tail currents measured at membrane potentials between -55 and $-25 \mathrm{mV}$. Because $I_{\mathrm{K} 1}$ inactivates with time constant of 400-800 msec (Simon et al., 1992), it was completely inactivated by the end of the $4 \mathrm{sec}$ pulse. Therefore, the time constants measured after the long pulse were deactivation time constants of $I_{\mathrm{K} 2}$, and the time constants measured after the short pulse were deactivation time constants of $I_{\mathrm{K} 1}$. Postpulses above $-25 \mathrm{mV}$ did not result in clearly decaying currents, and postpulses below $-55 \mathrm{mV}$ were too close to the reversal potential to produce a clear tail current. For measuring the time constraints, a $5 \mathrm{msec}$ initial period of the postpulse was omitted to allow the electrode to settle and establish voltage control. The cells were initially voltage-clamped at $-35 \mathrm{mV}$ so that the transient current $I_{\mathrm{A}}$ was inactivated.

At most membrane potentials measured, there was significant difference between time constants of deactivation after a short prepulse versus a long prepulse (Fig. $3 C$ ). The current, activated with a brief prepulse, deactivated with a time constant between 20 and $50 \mathrm{msec}$. This range is consistent with the deactivation rates reported in Simon et al. (1992), in which deactivation time constants were measured after a $75 \mathrm{msec}$ prepulse. After a $4 \mathrm{sec}$ prepulse, however, the current deactivated with a time constant between 100 and $250 \mathrm{msec}$.

\section{Deactivation of $I_{K}$ in the presence and absence of FMRFamide}

Deactivation time constants of $I_{\mathrm{K} 2}$ were measured and compared in the absence and presence of FMRFamide. Cells were voltageclamped at $-70 \mathrm{mV}$, and a $6 \mathrm{sec}$ pulse to $0 \mathrm{mV}$ was applied, followed by a $4 \mathrm{sec}$ postpulse to potentials ranging from $-100 \mathrm{mV}$ to $-40 \mathrm{mV}$ (Fig. $4 A$ ). Difference currents were obtained by subtracting leak-subtracted current traces measured in the absence of FMRFamide from current traces, corresponding to the same voltage pulse, measured in the presence of FMRFamide. An increase in the size of the currents measured during successive prepulses to $0 \mathrm{mV}$ was observed in FMRFamide. This increase indicated accumulation of an outward current over several pulses (Fig. 4A).

The amplitude of the difference current at the beginning of the postpulse was plotted against membrane potential (Fig. $4 B$ ). This $I-V$ plot shows that the reversal potential of the difference current is between $-70 \mathrm{mV}$ and $-60 \mathrm{mV}$. This estimate for the reversal potential is consistent with previous estimates of $E_{\mathrm{K}}$ in leech heart interneurons (Simon et al., 1992). The difference currents measured at membrane potentials above the reversal potential were generally smaller than those measured at membrane potentials below the reversal potential. Compare the size of currents measured at $-40 \mathrm{mV}$ with those measured at $-90 \mathrm{mV}$ in Figure $4 B$. This difference in amplitude was independent of the order of the postpulse potentials applied, and it suggests that the channels involved may pass current preferentially in the inward direction.

Using the tail currents, deactivation time constants were measured in the absence and presence of FMRFamide. At potentials above the reversal potential of the difference current, there was no significant difference between deactivation time constants in the absence and presence of FMRFamide. At membrane potentials of $-70 \mathrm{mV}$ and below, however, the decay of tail currents was significantly slower ( $t$ test; $p<0.05 ; n=7$ ) in the presence of FMRFamide than the decay in the absence of FMRFamide (Fig. $4 C$ ). It is not possible to measure the decay of tail currents near reversal and thus determine whether there is also significant slowing in the important physiological range around $-60 \mathrm{mV}$; however, the fact that $I_{\mathrm{K}}$ deactivates very slowly in the presence of FMRFamide at membrane potentials below $-70 \mathrm{mV}$ suggests that the deactivation may also be slow around the reversal potential. Slow deactivation of $I_{\mathrm{K}}$ in the presence of FMRFamide at membrane potentials around $-60 \mathrm{mV}$ could help activate the 
A
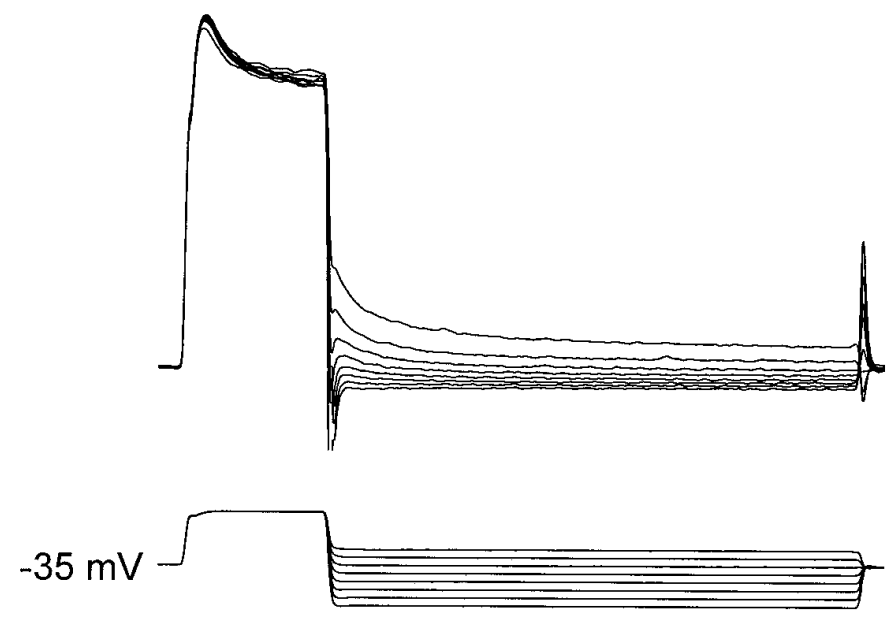

$60 \mathrm{~ms}$

B
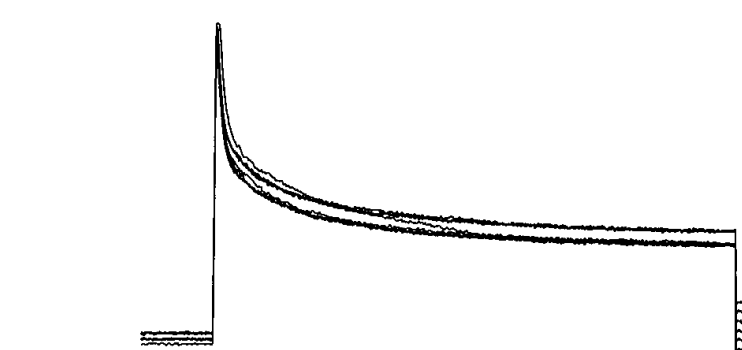

(1)
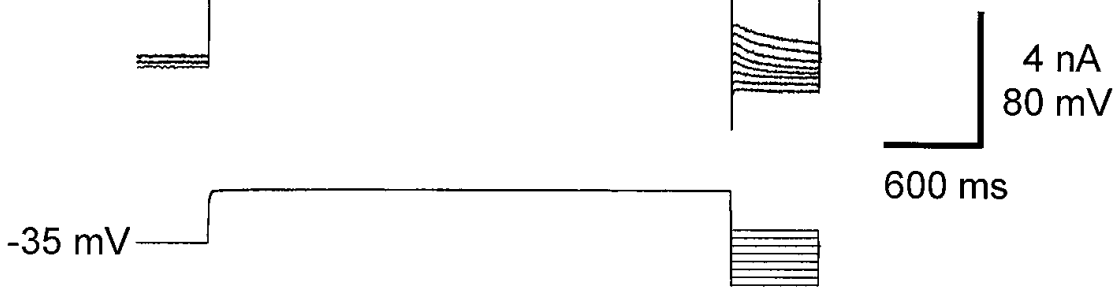

$600 \mathrm{~ms}$
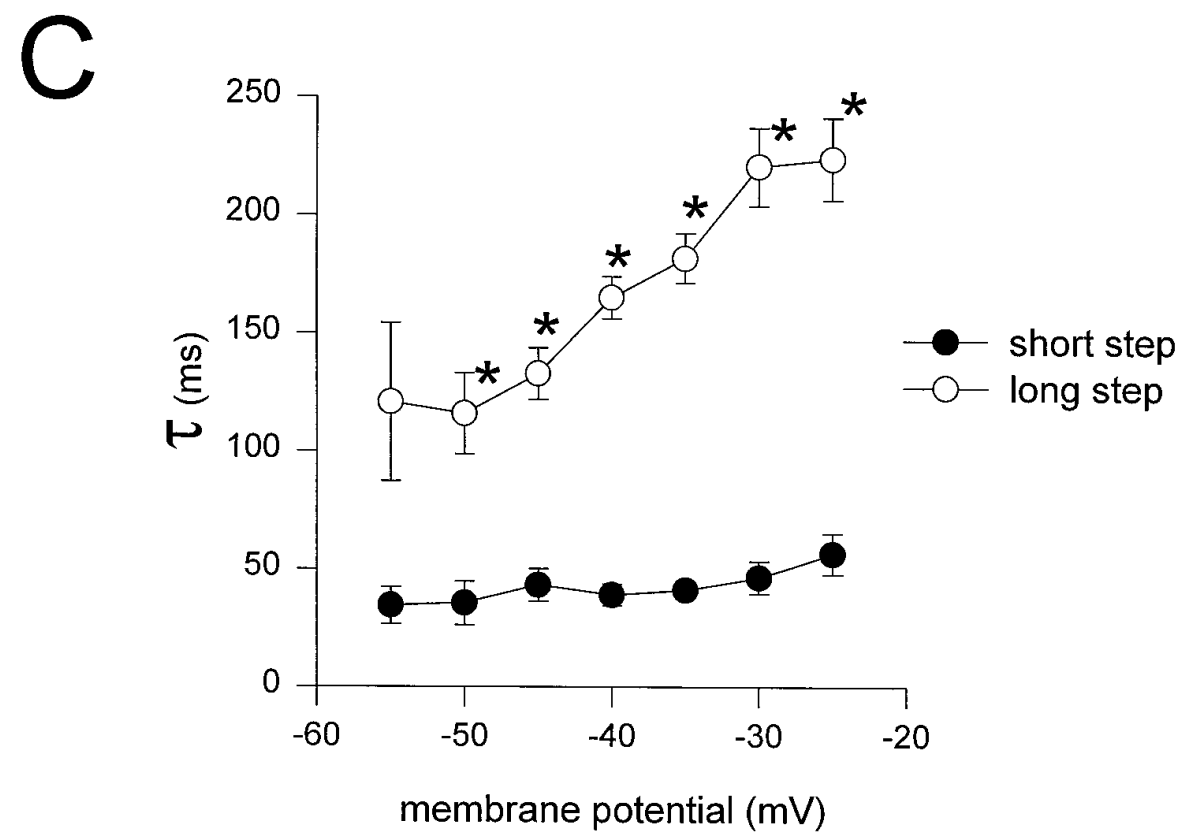

Figure 3. Deactivation time constants for $I_{\mathrm{K}}$. Cells were voltage-clamped at $-35 \mathrm{mV}$. Outward currents were activated by a prepulse to $0 \mathrm{mV}$. The prepulse was followed immediately by a postpulse from $-60 \mathrm{mV}$ to $-25 \mathrm{mV}$, in steps of $5 \mathrm{mV}$. $A$, Currents used to measure deactivation time constants after a brief (100 msec) activation prepulse. $B$, Currents used to measure deactivation time constants after a long (4 sec) activation prepulse. $C$, Plot of average deactivation time constants against membrane potential after a short (solid circles) or a long (open circles) prepulse (mean \pm SEM; $n=6)$. Asterisks indicate values that are significantly different $(t$ test; $p<0.01)$. 
A
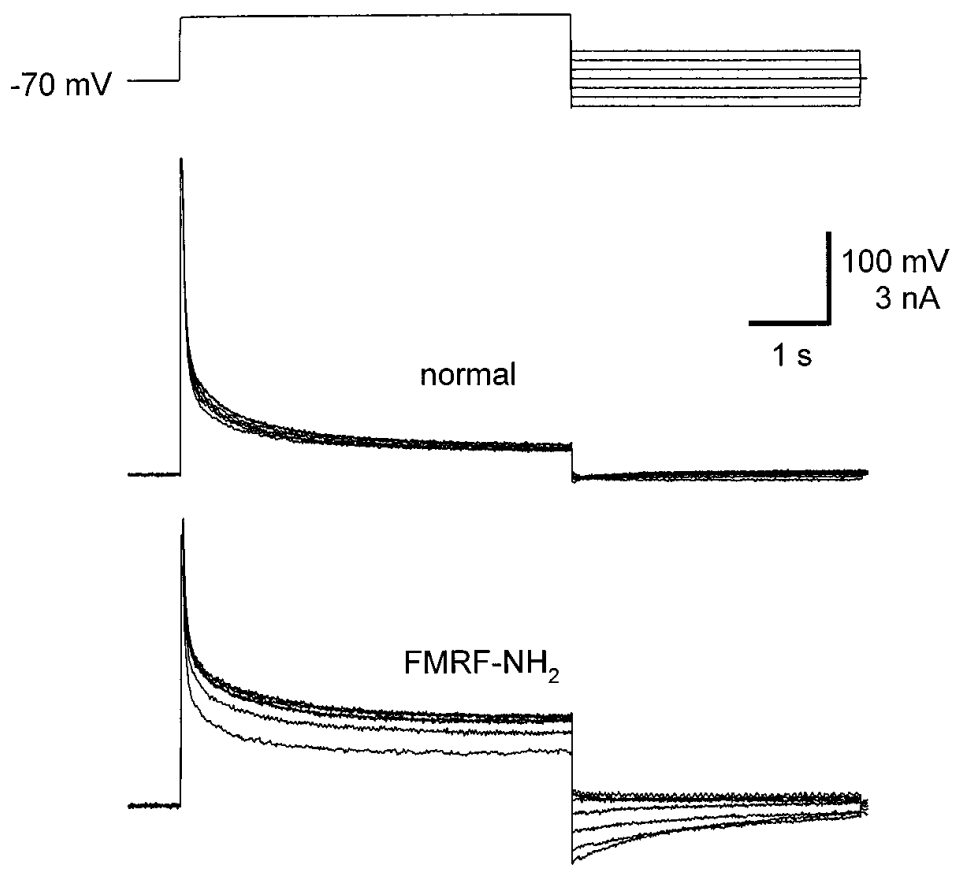

difference

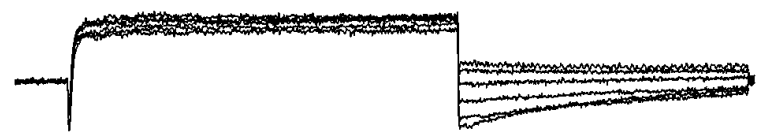

B

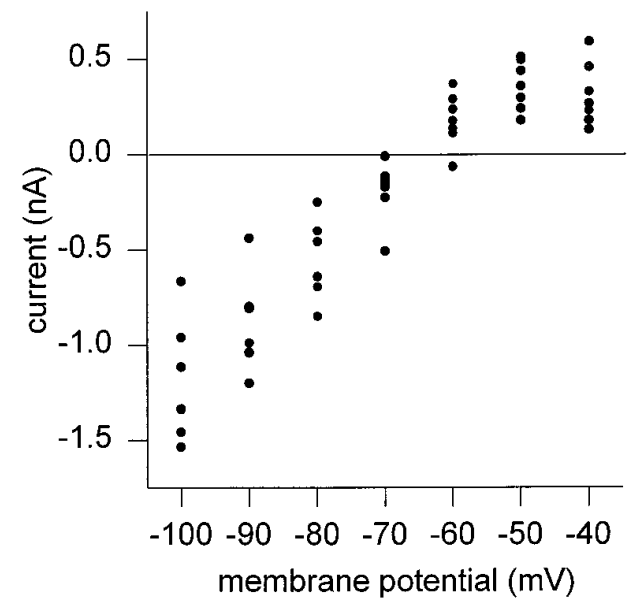

C

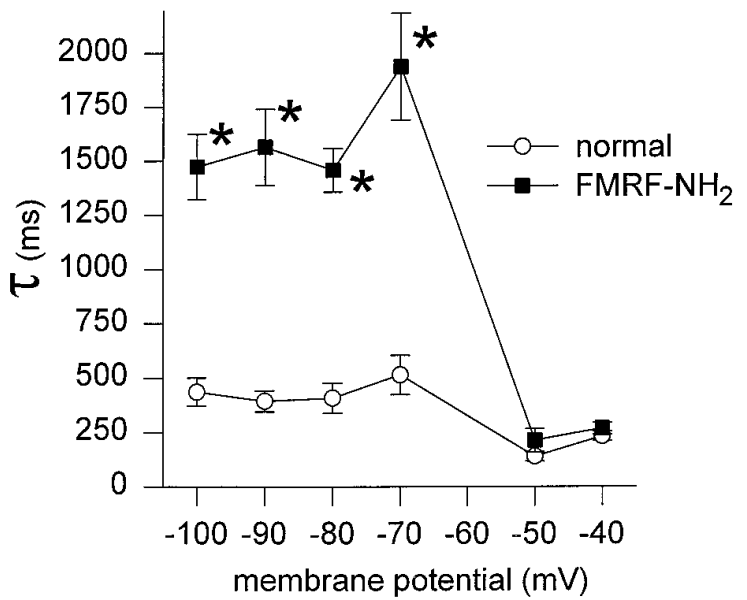

Figure 4. Tail currents of $I_{\mathrm{K}}$ in the absence and presence of FMRFamide. $A$, Leak-subtracted outward currents measured by applying a 6 sec depolarizing pulse to $0 \mathrm{mV}$ from a holding potential of $-70 \mathrm{mV}$, followed immediately by $4 \mathrm{sec}$ pulses from $-100 \mathrm{mV}$ to $-40 \mathrm{mV}$, in steps of $10 \mathrm{mV}$. In the absence of FMRFamide, tail currents were small, whereas large tail currents were observed in the presence of $10^{-6} \mathrm{M}$ FMRFamide. Currents measured in the absence of FMRFamide were subtracted from currents measured in the presence of FMRFamide to reveal the difference current. $B$, The $I-V$ plot of tail currents. Currents were measured from traces of the difference current at the beginning of postpulse. The current values indicate that the reversal potential of the difference current is between $-70 \mathrm{mV}$ and $-60 \mathrm{mV}$. C, Plot of deactivation time constants against membrane potential in the presence (solid squares) and absence (open circles) of FMRFamide. Tail currents in the presence of FMRFamide were not only larger in magnitude, but also had a slower decay rate at membrane potentials of $-70 \mathrm{mV}$ and below. Asterisks indicate values that are significantly different $(t$ test; $p<0.05 ; n=7)$.

hyperpolarization-activated inward current $I_{\mathrm{h}}$, as it does in the model described in Results.

\section{FMRFamide activates a slowly activating outward current $I_{K F}$}

To reveal any slowly activating outward current that might be elicited by FMRFamide, we used a long depolarizing protocol and compared the activation of $I_{\mathrm{K}}$ in the absence and presence of FMRFamide. From a holding potential of $-70 \mathrm{mV}$, a $17.5 \mathrm{sec}$ pulse to $0 \mathrm{mV}$ was applied and followed by an $8 \mathrm{sec}$ pulse to -100 $\mathrm{mV}$ to reveal any tail currents. This protocol was used in both the absence and presence of FMRFamide, and leak-subtracted current traces were used to obtain the difference current (Fig. 5). The difference current during the depolarizing pulse to $0 \mathrm{mV}$ comprised an initial transient inward current followed by a slowly activating outward current $(\tau=10-12 \mathrm{sec})$. The slowly activating outward current was also slow in deactivation $(\tau=2-3 \mathrm{sec})$, resulting in a large tail current. The transient inward current was possibly caused by the negative shift of inactivation steady-state of $I_{\mathrm{K} 1}$ in FMRFamide, as reported by Simon et al. (1992) (see Discussion). We shall refer to this novel FMRFamide-sensitive slowly activating outward current as $I_{\mathrm{KF}}$.

We fit the difference current using the parameters given by Tables 1 and 2 (Fig. 5, bottom trace, dotted lines). A maximal conductance of $23 \mathrm{nS}$ for $I_{\mathrm{KF}}$ gave a good fit of the current in response to the step pulse to $0 \mathrm{mV}$, but underestimated the tail current in response to the step down to $-100 \mathrm{mV}$. A good fit of the tail current was obtained by increasing the maximal conductance threefold to $70 \mathrm{nS}$. The increase in conductance to obtain a good fit of the tail current confirms that $I_{\mathrm{KF}}$ is larger as an inward current than as an outward current. 

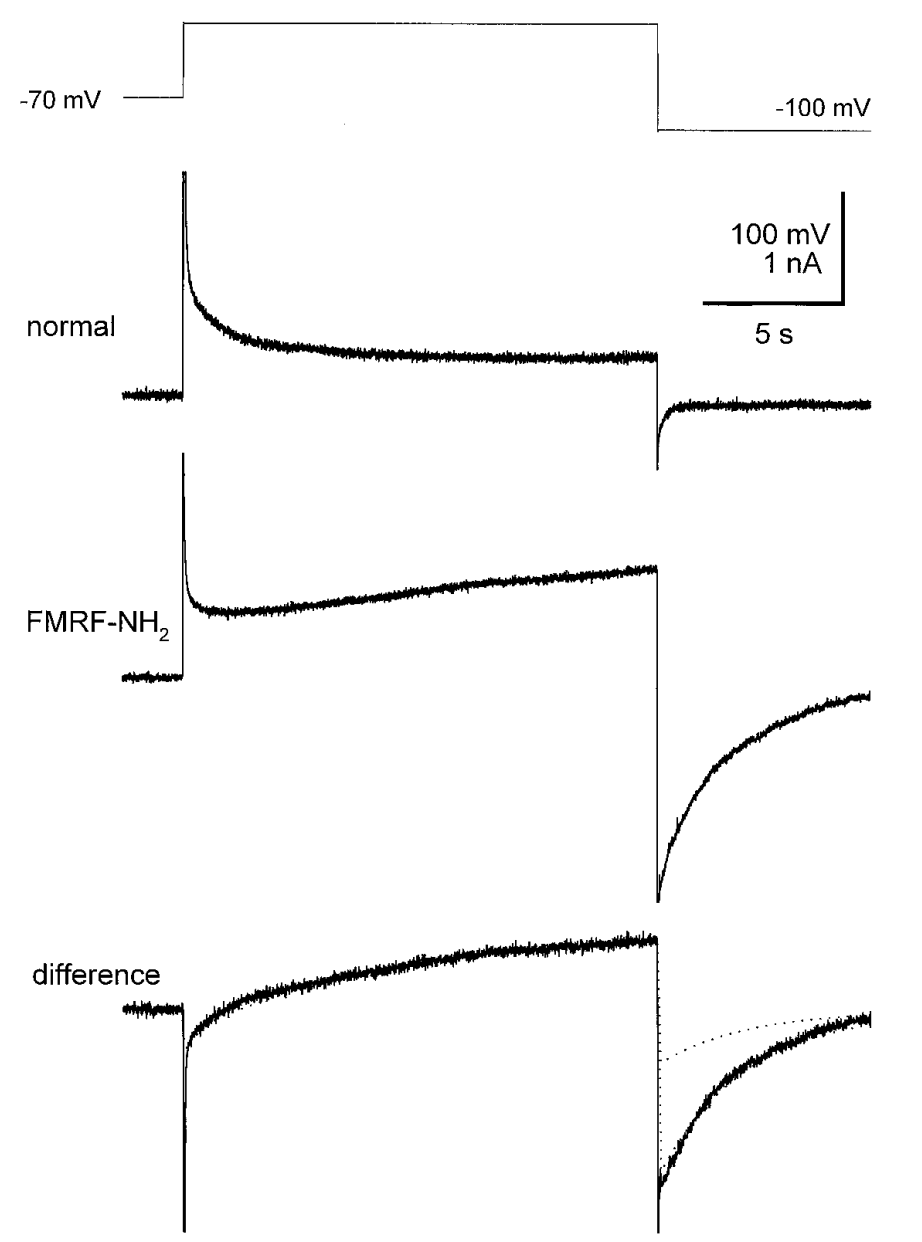

Figure 5. Bath application of FMRFamide activates a slowly activating outward current. From a holding potential of $-70 \mathrm{mV}$, outward currents were activated by a $17.5 \mathrm{sec}$ depolarizing pulse to $0 \mathrm{mV}$, followed by an 8 sec pulse to $-100 \mathrm{mV}$ to reveal the tail current. This protocol was used in both the absence and presence of FMRFamide, and a difference current was obtained by subtracting the traces. The difference current (bottom trace $)$ reveals a slowly activating $(\tau=9 \mathrm{sec})$ outward current that deactivated slowly $(\tau=3 \mathrm{sec})$ as well. The difference current was fit using the parameters given by Tables 1 and 2 (bottom trace, dotted lines). A maximal conductance of $23 \mathrm{nS}$ for $I_{\mathrm{KF}}$ gave a good fit of the current in response to the step pulse to $0 \mathrm{mV}$, but underestimated the tail current in response to the step down to $-100 \mathrm{mV}$. A good fit of the tail current was obtained by increasing the maximal conductance to $70 \mathrm{nS}$.

\section{Activation of $\boldsymbol{I}_{K F}$}

To measure activation of $I_{\mathrm{KF}}$, we voltage-clamped the cells at -70 $\mathrm{mV}$ and activated outward currents using six depolarizing steps to membrane potentials from $-50 \mathrm{mV}$ to $0 \mathrm{mV}$, both in the absence and in the presence of FMRFamide (Fig. 6A). A time interval of at least $30 \mathrm{sec}$ was allowed between pulses in FMRFamide to allow the current to deactivate and therefore to prevent the accumulation of the current over several pulses. We used the amplitude of the difference current at the end of the pulse as a measurement of the activation $I_{\mathrm{KF}}$. A sample plot of $I_{\mathrm{KF}}$ (measured at the end of the pulse) against membrane potential is shown in Figure $6 \mathrm{~B}$. Assuming a reversal potential of $-65 \mathrm{mV}$, the $I_{\mathrm{KF}}$ conductance was calculated and plotted against membrane potential (Fig. 6C). Because the conductances did not saturate at $0 \mathrm{mV}$, a steady-state activation curve was not plotted. Voltage pulses to potentials higher than $0 \mathrm{mV}$ were not used because good voltage clamp could not be obtained at such potentials. Also, because of difficulty in keeping the cells at depolarized potentials for long periods of time, the length of the activating pulse was restricted to $12 \mathrm{sec}$, even though the current did not completely activate in that period of time.

To observe the activation of $I_{\mathrm{KF}}$ over longer periods of time, and to observe how $I_{\mathrm{KF}}$ might be integrated during the oscillation of the heart interneurons, the following protocol was used. The cells were voltage-clamped at $-70 \mathrm{mV}$, a sequence of four $6 \mathrm{sec}$ pulses to $0 \mathrm{mV}$ was applied, and the time interval between these pulses was varied from 2 to $12 \mathrm{sec}$ (Fig. 7A). Over the four pulses, the amplitude of the outward current increased without saturating, provided the interpulse interval was brief $(2-6 \mathrm{sec})$. When the interpulse interval was increased to $12 \mathrm{sec}$, there was an increase an the amplitude of $I_{\mathrm{K}}$ from the first to the second pulse, and a smaller increase from the second to third pulse. In all measurements with a $12 \mathrm{sec}$ interpulse interval, the current eventually saturated, and there was little or no increase in $I_{\mathrm{K}}$ from the third to the fourth pulse. Figure $7 B$ shows the difference between the amplitude of $I_{\mathrm{K}}$ at the end of the first pulse and at the end of each consecutive pulse for traces plotted in Figure $7 A$. The difference between the fourth-pulse and first-pulse amplitude of $I_{\mathrm{K}}$ was more than double when the interpulse interval was 2 sec (black) as compared with $12 \mathrm{sec}$ (white). The $6 \mathrm{sec}$ interpulse period (gray) resulted in an increase in $I_{\mathrm{K}}$ that was intermediate between the 2 sec interval and the $12 \mathrm{sec}$ interval case. It should be noted that the increased amplitude of the $I_{\mathrm{K}}$ does not decay during the $12 \mathrm{sec}$ intervals between pulses. This fact, together with our measurements of the deactivation of $I_{\mathrm{K}}$ in the presence of FMRFamide (Fig. $4 C$ ), implies that there is a residual part of the current that remains active despite the long wait intervals in our voltage-clamp protocols.

\section{$I_{K F}$ speeds up the oscillation of model heart interneurons}

Simon et al. (1992) showed that bath application of FMRFamide at low concentrations $\left(\leq 5 \times 10^{-8} \mathrm{M}\right)$ causes an increase in the oscillation rate of heart interneurons (Fig. $8 A$ ). The increase in the oscillation rate is reversed by washing out the FMRFamide. We used our model of a reciprocally inhibitory pair of heart interneurons (Nadim et al., 1995; Olsen et al., 1995) to test the effect of $I_{\mathrm{KF}}$ on the oscillation of model cells. The current $I_{\mathrm{KF}}$ was modeled as a noninactivating, slowly activating, and slowly deactivating $\mathrm{K}^{+}$current:

$$
I=g_{\max } m\left(V-E_{\mathrm{K}}\right) .
$$

The activation variable $m$ was governed by Equation 2, where the steady-state activation curve $m_{\infty}$ is given by Equation 3 . The parameters defining the model $I_{\mathrm{KF}}$ are given in Tables 1 and 2. The maximal conductance of $I_{\mathrm{KF}}$ was increased from 0 to $40 \mathrm{nS}$ over 40 sec, held at $40 \mathrm{nS}$ for $20 \mathrm{sec}$, and then reduced back to 0 over $40 \mathrm{sec}$. Addition of $I_{\mathrm{KF}}$ reduced the period of oscillations in the model heart interneurons from $7.8 \mathrm{sec}$ to $5.6 \mathrm{sec}$. Analysis of the ionic currents in the model cells revealed two factors that contributed to the acceleration of the rhythm: additional activation of the hyperpolarizationactivated inward current $I_{\mathrm{h}}$ and decrease in spike frequency, and therefore spike-mediated synaptic transmission. $I_{\mathrm{h}}$ increased because the slow deactivation of $I_{\mathrm{KF}}$ caused the model membrane potential to approach $E_{\mathrm{K}}$ more closely and linger there. Additional activation of $I_{\mathrm{h}}$ caused the model cells to escape more quickly from the inhibited phase and hence reduced the period of oscillations. This effect was similar to increasing the maximal conductance of $I_{\mathrm{h}}$, as described in 
A
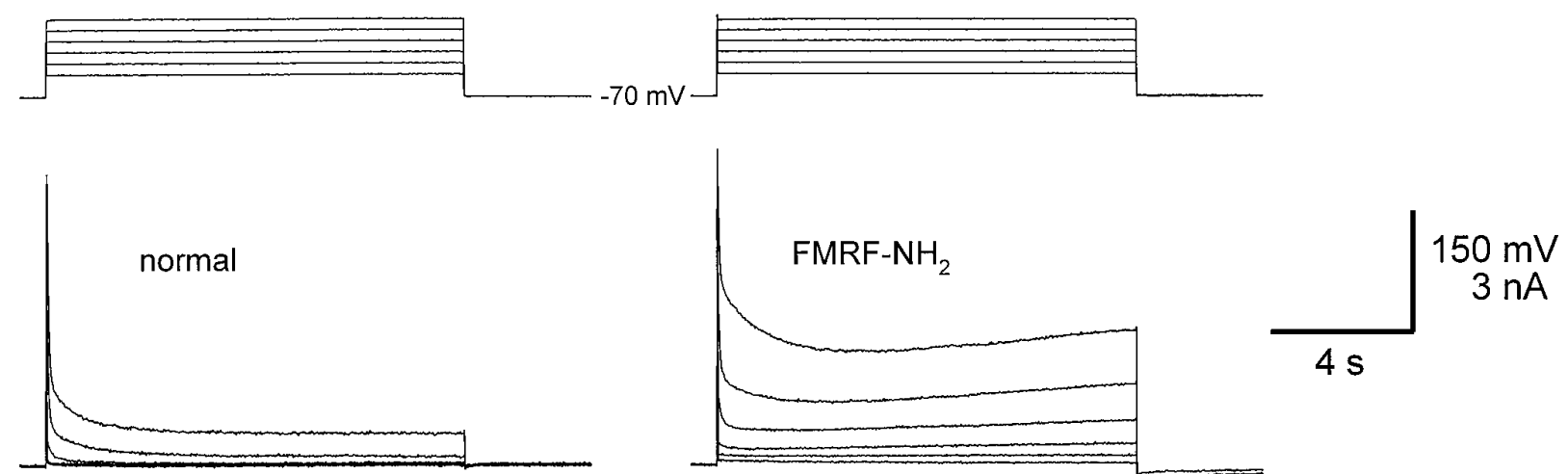

B
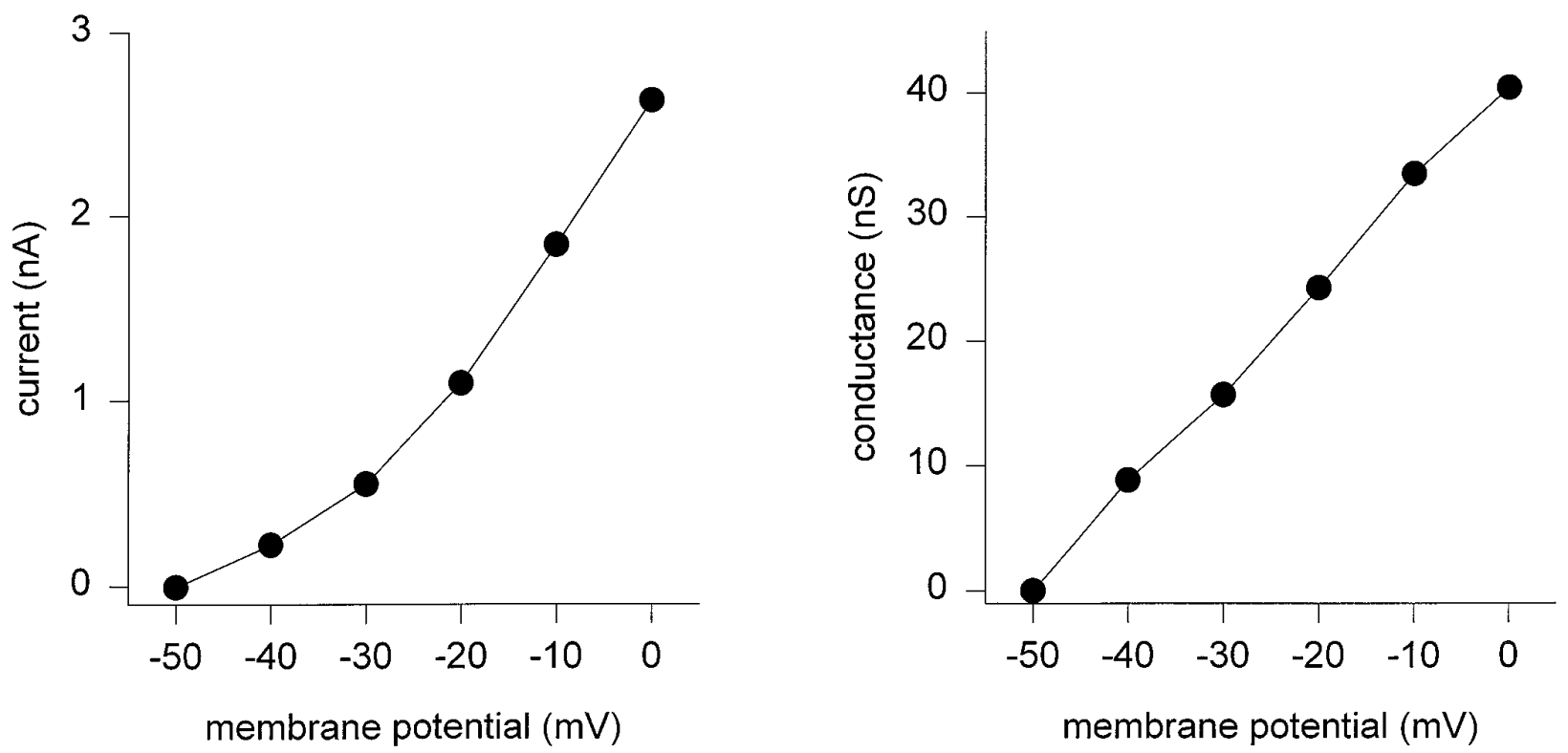

Figure 6. Activation of $I_{\mathrm{KF}}$. A, Currents activated from a holding potential of $-70 \mathrm{mV}$ using a series of 12 sec depolarizing steps from $-50 \mathrm{mV}$ to $0 \mathrm{mV}$. Currents obtained in the absence (left panel) and presence (right panel) of FMRFamide. B, Current-voltage relationship of the difference current at the end of the $12 \mathrm{sec}$ depolarizing step. $C$, Conductance of the difference current $I_{\mathrm{KF}}$ at the end of the 12 sec depolarizing step shown against membrane potential. To calculate conductance, the reversal potential of $I_{\mathrm{KF}}$ was assumed to be $-65 \mathrm{mV}$.

Olsen et al. (1995). The decrease in spike frequency in the model cell resulted in less spike-mediated inhibition onto the contralateral cell, in turn allowing the contralateral cell to escape inhibition more easily, hence speeding up the oscillation. According to Nadim et al. (1995) and Olsen et al. (1995), spike-mediated inhibition is the dominant form of synaptic transmission in the oscillation of model heart interneurons, and possibly in the oscillation of the heart interneurons themselves. The effect of $I_{\mathrm{KF}}$ in reducing the spike frequency was similar to the effect of increasing the maximal conductance of $I_{\mathrm{K} 2}$, as described in Olsen et al. (1995).

\section{The heart interneuron model neurons were improved using the new data}

We used the new kinetic equations for $I_{\mathrm{K} 1}, I_{\mathrm{K} 2}$, and $I_{\mathrm{A}}$ in the model of heart interneurons described in Nadim et al. (1995) and Olsen et al. (1995). In Nadim et al. (1995), we had reported that the model cells reproduce the behavior of the biological cells in producing oscillations in reduced- $\mathrm{Na}^{+}$saline (slow oscillations). To produce these oscillations, however, the maximal conductance of the graded synaptic current $\left(g_{\text {SynG }}\right)$ in the cells had to be increased from the experimentally measured value of 20-30 nS to $300 \mathrm{nS}$. With the new kinetic equations for the outward currents, the model cells reproduced the slow oscillations with $g_{\text {SynG }}=30$ nS (Fig. 9). This improvement in the model was caused by the slow deactivation of $I_{\mathrm{K} 2}$. During the depolarized phase of the oscillations, $I_{\mathrm{K} 2}$ was activated, counteracting the depolarizing effect of the inward currents. During the inhibited phase, $I_{\mathrm{K} 2}$, because of its slow deactivation time constant, pulled the membrane potential toward the reversal potential of $\mathrm{K}^{+}(-75 \mathrm{mV})$ and caused a delay in the rise of the membrane potential. This delay resulted in removal of inactivation from the $\mathrm{Ca}^{2+}$ currents, which were re- 
A

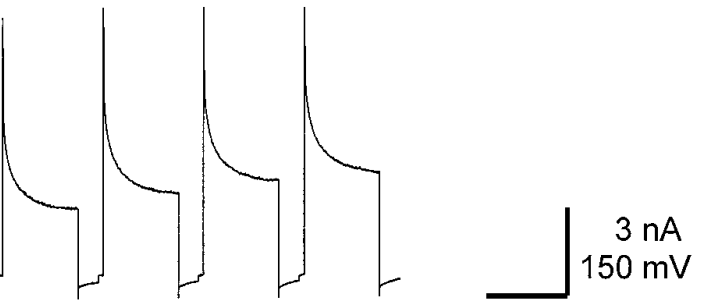

$-70 \mathrm{mV}$

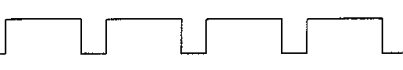

$6 \mathrm{~s}$

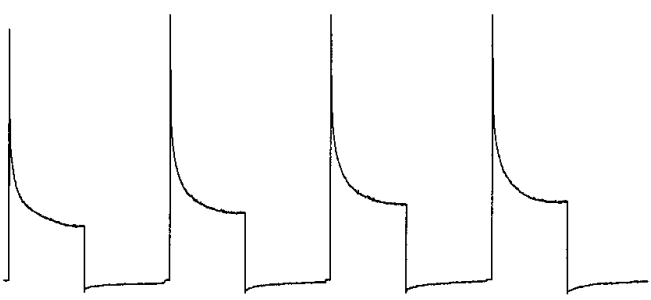

$-70 \mathrm{mV}$
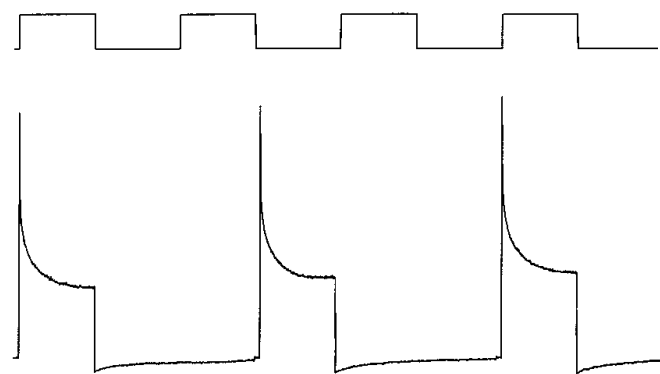

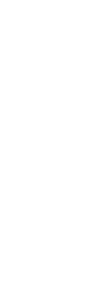

$-70 \mathrm{mV}$

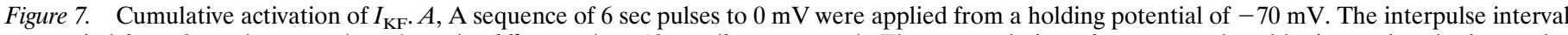

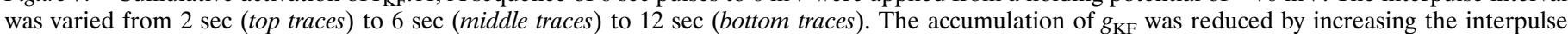

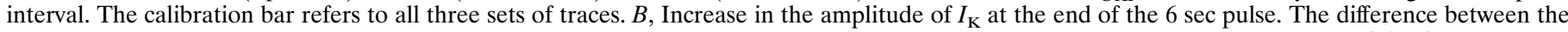

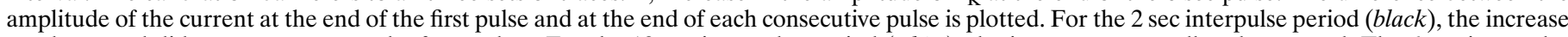

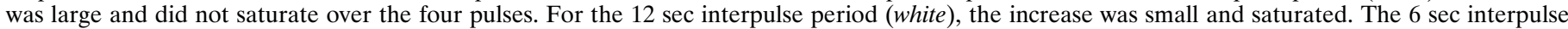
period (gray) was intermediate between the $2 \mathrm{sec}$ interval and the $12 \mathrm{sec}$ interval case in amplitude increase.

sponsible for producing the graded synaptic transmission in the model cells (Nadim et al., 1995). The increase in the $\mathrm{Ca}^{2+}$ currents resulted in sufficient graded synaptic transmission in the opposite cell to keep the oscillation stable.

\section{DISCUSSION}

From model to experiment: outward currents revisited

In Nadim et al. (1995), we described a realistic conductance-based model of the elemental two-cell oscillator that gives rise to rhythmic activity underlying the leech heartbeat. Analysis of the model cells predicted activation levels of ionic currents that were confirmed in experiments in which oscillator interneurons were voltage-clamped using realistic waveforms (Olsen and Calabrese, 1996). Moreover, this model has suggested potential mechanisms for modulation of cycle period in the real heart interneurons.

Our previous studies of outward currents in leech heart interneurons (Simon et al., 1992) showed that they comprise three components: a rapidly inactivating A-like current $I_{\mathrm{A}}$, a slowly inactivating component $I_{\mathrm{K} 1}$, and a noninactivating com-

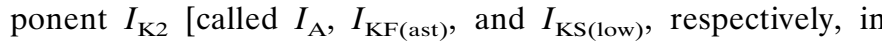
Simon et al., (1992)]. Sensitivity analysis on the model heart interneurons showed that the period of oscillation is particu- larly sensitive to variations in $I_{\mathrm{K} 1}$ and $I_{\mathrm{K} 2}$ (Olsen et al., 1995). Simon et al. (1992) showed that FMRFamide affects the steadystate inactivation and to a smaller extent the steady-state activation of $I_{\mathrm{K} 1}$ (and $I_{\mathrm{K} 2}$ ) by shifting these curves to more negative potentials. In particular, from a holding potential of $-70 \mathrm{mV}$, there would be more inactivation of $I_{\mathrm{K} 1}$ in the presence of FMRFamide. The additional inactivation in FMRFamide could explain why the difference current in Figure 5 is initially negative. We observed the initial negative current in most difference currents measured. If, however, several depolarizing pulses were applied in a sequence in the presence of FMRFamide, the cumulative activation of $I_{\mathrm{KF}}$ eventually became larger than the initial extra inactivation of $I_{\mathrm{K} 1}$, and the initial negative difference current was obscured.

Because the measurements of activation of $I_{\mathrm{K}}$ performed by Simon et al. (1992) applied to the sum of both currents $I_{\mathrm{K} 1}$ and $I_{\mathrm{K} 2}$, from their data it was inconclusive whether $I_{\mathrm{K} 1}$ and $I_{\mathrm{K} 2}$ have different activation and deactivation time courses. We show that such a difference has large effects on oscillations in the model heart interneurons (Fig. 2). Whether FMRFamide shifts the steady-state activation curve of $I_{\mathrm{K} 2}$ could also not be determined from experiments described in Simon et al. (1992). To examine 


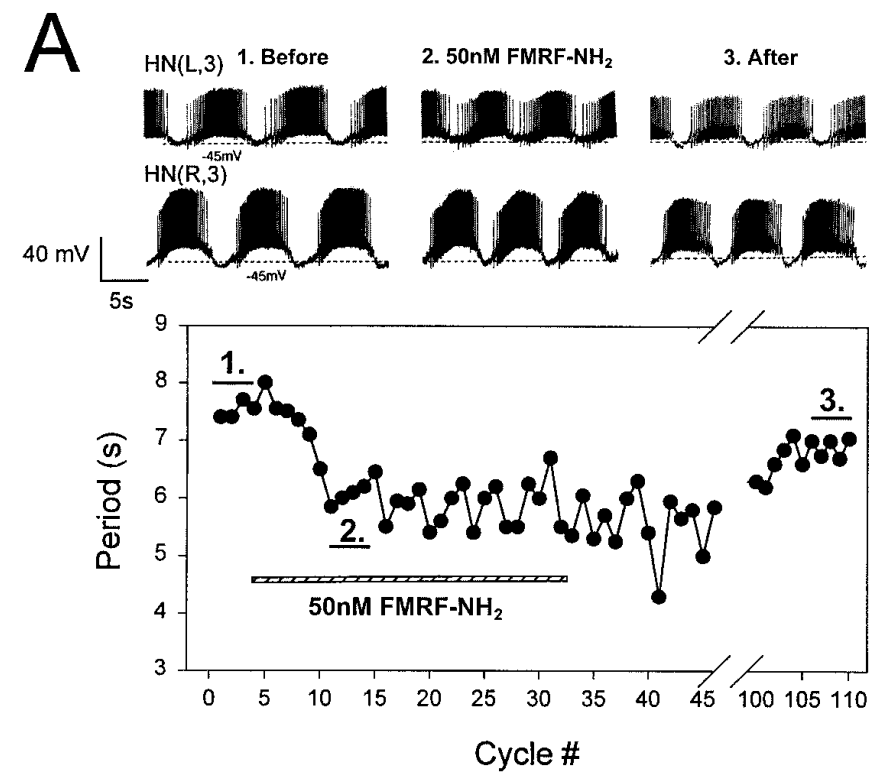

B
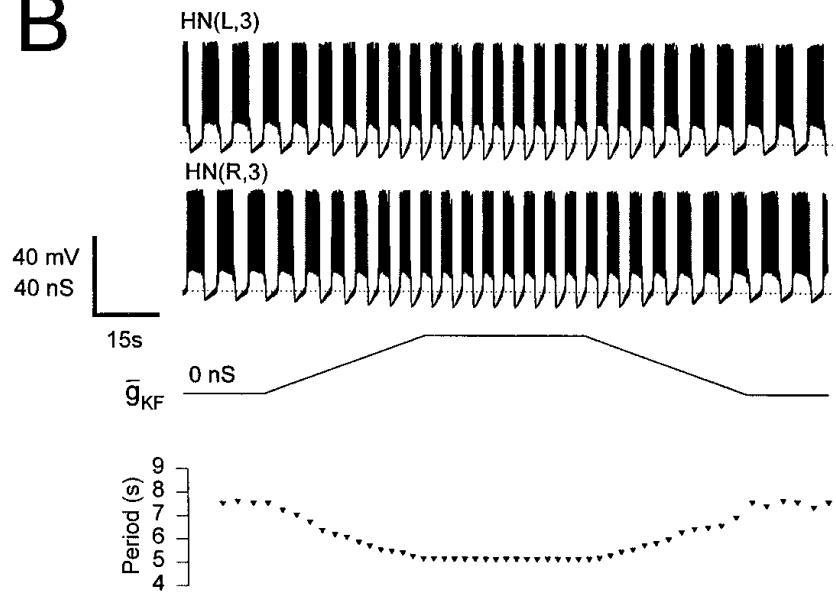

Figure 8. Acceleration of the heartbeat rhythm by FMRFamide. $A$, The period of the activity rhythm in oscillator heart interneurons $(H N)$ is reduced from $7.5-8.5 \mathrm{sec}$ to $\sim 6 \mathrm{sec}$ by bath application of $5 \times 10^{-8} \mathrm{M}$ FMRFamide. $B$, The effect of FMRFamide is mimicked in the model heart interneurons by introducing $I_{\mathrm{KF}}$ and shifting the steady-state inactivation curve of $I_{\mathrm{K} 1}$ by $-10 \mathrm{mV}$ (i.e., to the left). Simon et al. (1992) demonstrated that FMRFamide produced such a negative shift in steadystate inactivation of $I_{\mathrm{K} 1}$. HN cells are indexed by ganglion number and body side.

this question, we needed to find experimental protocols to measure the activation or deactivation time constants of each current separately.

\section{The slow current $I_{K F}$ is not caused by a change in activation of $I_{K 2}$ in FMRFamide}

We were interested to see whether the activation of $I_{\mathrm{K} 2}$ is sensitive to FMRFamide. A standard activation voltage-clamp protocol in the absence and presence of FMRFamide seemed to indicate extra activation of $I_{\mathrm{K} 2}$ by FMRFamide. A scrutiny of the currents measured during automatic leak-subtraction steps, however, showed that the leak current after a depolarizing pulse had a time-dependent, decaying component. The nonlinearity observed in the measurement of the leak current indicated either slow activation or slow deactivation of a current that was inward at membrane potentials below $-70 \mathrm{mV}$. We hypothesized that in the

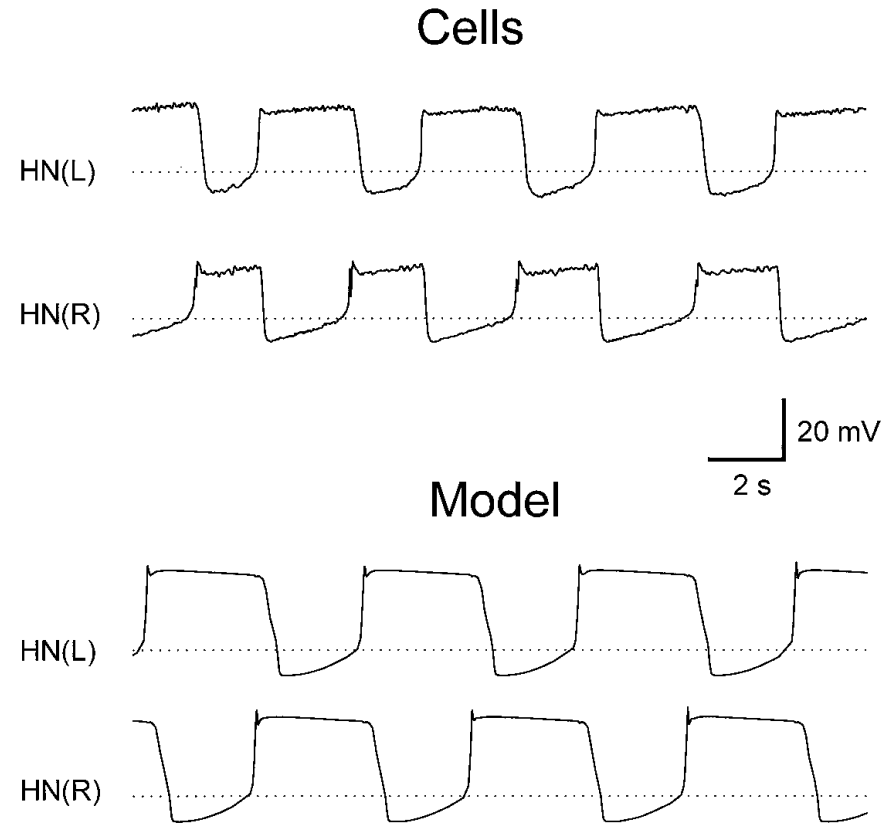

Figure 9. Slow oscillations of oscillator heart interneurons $(H N)$ of the third ganglion in $10 \% \mathrm{Na}^{+}$saline containing $5 \mathrm{mM} \mathrm{Ca}^{2+}$ (the normal $\left[\mathrm{Ca}^{2+}\right]$ is $1.8 \mathrm{mM}$ ) triggered by a hyperpolarizing pulse (not shown) in one cell. Similar oscillations are produced in the model cells by reducing $E_{\mathrm{Na}}$ and $E_{\mathrm{h}}$. The model cells are as described in Nadim et al. (1995), with $\mathrm{K}^{+}$ currents given by Equations 1 and 2, and Tables 1 and 2. The maximal conductance $g_{\text {SynG }}$ of the graded synaptic current is $30 \mathrm{nS}$, which is within the biological range of and an order of magnitude smaller than the value used in Nadim et al. (1995). HN cells are indexed by body side.

presence of FMRFamide a new current $I_{\mathrm{KF}}$ is activated, and we verified that the nonlinearity in the leak-subtraction steps was caused by the deactivation of $I_{\mathrm{KF}}$. We have not entirely excluded the possibility that the extra current activated in the presence of FMRFamide is attributable to a change in the kinetics of $I_{\mathrm{K} 2}$; however, when several long depolarizing voltage pulses are applied in a sequence, the extra current is activated cumulatively over these steps (Fig. 7), indicating very slow activation kinetics, whereas even during the first depolarizing pulse, $I_{\mathrm{K} 2}$ is activated. Therefore it is implausible that the new current is caused by a change in the activation kinetics of $I_{\mathrm{K} 2}$.

Because $I_{\mathrm{KF}}$ is very slow in activation, it activates cumulatively over a sequence of depolarizing pulses. Therefore, in Figures $3 B$ and $4 A$, there is cumulative activation of $I_{\mathrm{K}}$ over several pulses to the same potential. This cumulative activation, however, should not change the time constant of activation and deactivation measured, but just the amplitude.

\section{Auxiliary mechanisms may play a role in activation and deactivation of $\boldsymbol{I}_{\boldsymbol{K F}}$}

We have shown that the activation and deactivation of $I_{\mathrm{KF}}$ are voltage dependent, but the dependence is slow ( $\tau$ values of the order of seconds). There is a possibility that activation of $I_{\mathrm{KF}}$ is not solely a voltage-dependent process but that it is is also influenced by some internal second messenger: for example, $\mathrm{Ca}^{2+}$ released from internal stores. Such an "auxiliary" mechanism for activation is supported by the evidence that in addition to the voltage-dependent deactivation described in the results, there is a slower deactivation of $I_{\mathrm{KF}}$ in which after activation by a sequence of pulses the cell remains hyperpolarized by a few millivolts for a minute or two before returning to baseline. 
From experiment to model: activation of $I_{K F}$ may be one mechanism of modulation by FMRFamide of the heartbeat rhythm

Heartbeat in the leech has a period of $\sim 8-12 \mathrm{sec}$ at room temperature. Various sensory pathways and identified modulatory neurons can accelerate this rhythm of activity (Arbas and Calabrese, 1984, 1987). The target of this modulation must be the elemental two-cell oscillators that pace this centrally programmed rhythm. Among these modulatory pathways are the swim-gating interneuron cell 204 (Weeks and Kristan, 1978; Arbas and Calabrese, 1984). Activity in these neurons gates on the swimming motor pattern in both semi-intact preparations and in isolated nerve cords, and likewise accelerates the cycling of the heartbeat pattern generator. These neurons are immunoreactive (Kuhlman et al., 1985) for the endogenous neuropeptide FMRFamide (Evans et al., 1991), and bath-applied FMRFamide at lower concentrations $\left(\leq 5 \times 10^{-8} \mathrm{M}\right)$ accelerates the cycling of the heartbeat pattern generator (Simon et al., 1992). Although several modulatory effects of FMRFamide have been documented in heartbeat oscillator interneurons (Simon et al., 1992, 1994; Schmidt et al., 1995), these changes cannot easily account for the observed acceleratory effects of FMRFamide or cell 204. Our results here suggest that in addition to the previously documented effects of FMRFamide, this peptide elicits a novel voltage-gated outward current, $I_{\mathrm{KF}}$, in oscillator heart interneurons. This current is characterized by very slow activation and deactivation kinetics. When this current is introduced into our model of an elemental two-cell oscillator, the cycling rate of the model increases. This result indicates that the primary effect of FMRFamide, which accounts for its acceleratory action on the heartbeat motor pattern, is its activation of $I_{\mathrm{KF}}$. The slow dynamics of $I_{\mathrm{KF}}$ give rise to a form of cellular memory similar to that observed when an artificial conductance based on the $\mathrm{Kv} 1.3\left(\mathrm{~K}^{+}\right)$channels, which have slow inactivation and deinactivation kinetics, was introduced into lobster stomatogastric neurons in culture (Turrigiano et al., 1996).

\section{From experiment to model: slow kinetics of $I_{K 2}$ contributed to slow oscillations}

When we modified our canonical model of a heart interneuron two-cell oscillator using the new measurements of $I_{\mathrm{K} 1}$ and $I_{\mathrm{K} 2}$ activation and deactivation kinetics, we discovered that slow oscillations in the model could now be produced with a realistic value of graded synaptic transmission $\left(g_{\text {SynG }}\right)$. Previously, $g_{\text {SynG }}$ had to be increased to $\sim 10$ times the value used in the canonical model (i.e., the realistic value) to produce oscillations in the absence of action potentials (Nadim et al., 1995). These oscillations are observed in heart interneurons when they are recorded in reduced $\mathrm{Na}^{+} /$high $\mathrm{Ca}^{2+}$ saline (Arbas and Calabrese, 1987; Nadim et al., 1995). During slow oscillations in the model, the slow deactivation of $I_{\mathrm{K} 2}$ helps keep the cells in the hyperpolarized phase long enough to remove inactivation from the low-threshold $\mathrm{Ca}^{2+}$ currents that are required for producing the plateau phase and graded inhibition during the slow oscillations. Therefore the large $g_{\text {SynG }}$ fudge factor that we used in Nadim et al. (1995) is now unnecessary. The new, more realistic value of $g_{\text {SynG }}$ does not affect the canonical model described in Nadim et al. (1995) and Olsen et al. (1995), because generation of oscillations in the canonical model depends primarily on spike-mediated transmission, and only minimally on graded transmission.

This reanalysis of outward currents in heart interneurons and their modulation by FMRFamide has solidified our detailed model of a heart interneuron two-cell oscillator and thus strengthened our understanding of how this half-center oscillator works. Our experiments demonstrate that a single neuromodulator affects multiple currents in a neuron, and analysis of these currents within the context of our model indicates that each makes a different functional contribution to the network behavior. Moreover, our results indicate that currents with very slow activation and deactivation kinetics can contribute substantially to pattern generation.

\section{REFERENCES}

Angstadt JD, Calabrese RL (1989) A hyperpolarization-activated inward current in heart interneurons of the medicinal leech. J Neurosci 9:2846-2857.

Angstadt JD, Calabrese RL (1991) Calcium currents and graded synaptic transmission between heart interneurons of the leech. J Neurosci 11:746-759.

Arbas EA, Calabrese RL (1984) Rate modification in the heartbeat central pattern generator of the medicinal leech. J Comp Physiol [A] 155:783-794.

Arbas EA, Calabrese RL (1987) Slow oscillations is membrane potential in interneurons that control heartbeat in the medicinal leech. J Neurosci 7:3953-3960.

Arshavsky YI, Orlovsky GN, Panchin YV, Roberts A, Soffe SR (1993) Neuronal control of swimming locomotion: analysis of the pteropod mollusc Clione and embryos of the amphibian Xenopus. Trends Neurosci 1993:16:227-233.

Calabrese RL, De Schutter (1992) Motor-pattern-generating networks in invertebrates: modeling our way toward understanding. Trends Neurosci 15:439-445.

Calabrese RL, Nadim F, Olsen ØH (1995) Heartbeat control in the medicinal leech: a model system for understanding the origin, coordination, and modulation of rhythmic motor patterns. J Neurobiol 27:390-402.

Dean J, Cruse H (1995) Motor pattern generation. In: The handbook of brain theory and neural networks (Arbib MA, ed), pp 600-605. Cambridge, MA: MIT.

Delcomyn F (1980) Neural basis of rhythmic behavior in animals. Science 210:492-498.

De Schutter E, Angstadt JD, Calabrese RL (1993) A model of graded synaptic transmission for use in dynamic network simulations. J Neurophysiol 69:1225-1235.

Dickinson PS (1995) Neuromodulation in invertebrate nervous systems. In: The handbook of brain theory and neural networks (Arbib MA, ed), pp 631-634. Cambridge, MA: MIT.

DiFrancesco D, Noble D (1989) Current $I_{\mathrm{f}}$ and its contribution to cardiac pacemaking. In: Neuronal and cellular oscillators (Jacklet JW, ed), pp 31-58. New York: Marcel Dekker.

Evans BD, Pohl J, Kartsonis NA, Calabrese RL (1991) Identification of RFamide neuropeptides in the medicinal leech. Peptides 12:897-908.

Getting PA (1989) Emerging principles governing the operation of neural networks. Annu Rev Neurosci 12:184-204.

Golowasch J, Marder E (1992) Proctolin activates an inward current whose voltage dependence is modified by external $\mathrm{Ca}^{2+}$. J Neurosci 12:810-817.

Harris-Warrick RM (1993) Pattern generation. Curr Opin Neurobiol 3:982-988

Harris-Warrick RM, Marder E (1991) Modulation of neural networks for behavior. Annu Rev Neurosci 14:39-57.

Harris-Warrick RM, Coniglio LM, Levini RM, Gueron S, Guckenheimer J (1995) Dopamine modulation of two subthreshold currents produces phase shifts in activity of an identified motoneuron. J Neurophysiol 74:1401-1420.

Hodgkin AL, Huxley AF (1952) A quantitative description of membrane current and its application to conduction and excitation in nerve. J Physiol (Lond) 117:500-544.

Jacklet JW (1989) Neuronal and Cellular Oscillators. New York: Marcel Dekker.

Johnson BR, Peck JH, Harris-Warrick RM (1995) Distributed amine modulation of graded chemical transmission in the pyloric network of the lobster stomatogastric ganglion. J Neurophysiol 72:437-452. 
Katz PS (1996) Neurons, networks, and motor behavior. Neuron $16: 245-253$.

Kuhlman JR, Li C, Calabrese RL (1985) FMRF-amide-like substances in the leech. I. Immunocytochemical localizataion. J Neurosci 5:2301-2309.

Lu J, Dalton IV JF, Stokes DR, Calabrese RL (1997) Functional role of $\mathrm{Ca}^{2+}$ currents in graded and spike-mediated synaptic transmission between leech heart interneurons. J Neurophysiol, in press.

Marder E, Calabrese RL (1996) Principles of rhythmic motor pattern generation. Physiol Rev 76:687-717.

Nadim F, Olsen $\varnothing \mathrm{H}$, De Schutter E, Calabrese RL (1995) Modeling the leech heartbeat elemental oscillator: I. Interactions of intrinsic and synaptic currents. J Computat Neurosci 2:215-235.

Olsen ØН (1994) Exploring temporal computation in neuronal systems. $\mathrm{PhD}$ thesis, University of Glasgow.

Olsen ØH, Calabrese RL (1996) Activation of intrinsic and synaptic currents in leech heart interneurons by realistic waveforms. J Neurosci 16:4858-4970.

Olsen $\varnothing \mathrm{H}$, Nadim F, Calabrese RL (1995) Modeling the leech heartbeat elemental oscillator: II. Exploring the parameter space. J Computat Neurosci 2:237-257.

Opdyke CA, Calabrese RL (1994) A persistent sodium current contrib- utes to oscillatory activity in heart interneurons of the medicinal leech. J Comp Physiol [A] 175:781-789.

Rossignol S, Dubuc R (1994) Spinal pattern generation. Curr Opin Neurobiol 4:894-902.

Schmidt J, Calabrese RL (1992) Evidence that acetylcholine is an inhibitory transmitter of heart interneurons in the leech. J Exp Biol 171:339-347.

Schmidt J, Gramoll S, Calabrese RL (1995) Segment-specific effects of FMRFamide on membrane properties of heart interneurons in the leech. J Neurophysiol 74:1485-1497.

Sharp AA, O’Neil MB, Abbott LF, Marder E (1993) Dynamic clamp: artificial conductances in biological neurons. Trends Neurosci 16:389-394.

Simon TW, Opdyke CA, Calabrese RL (1992) Modulatory effects of FMRFamide on outward currents and oscillatory activity in heart interneurons of the medicinal leech. J Neurosci 12:525-537.

Simon TW, Schmidt J, Calabrese RL (1994) Modulation of highthreshold transmission between heart interneurons of the medicinal leech by FMRF-NH2. J Neurophysiol 71:454-466.

Turrigiano GG, Marder E, Abbott LF (1996) Cellular short-term memory from a slow potassium conductance. J Neurophysiol 75:963-966. 